\title{
Preventing Sexual Abuse of Children and Adolescents with Disabilities - Evaluation Results of a Prevention Training for University Students
}

\author{
Karla Verlinden, Sara Scharmanski, Katharina Urbann and Pia Bienstein \\ University of Cologne, Germany
}

\begin{abstract}
This paper presents first results of the Cologne (Germany) evaluation study about a prevention training for University students. University students of special needs education $(N=391)$ received a special prevention training on sexual abuse of children and adolescents with disabilities. The training was evaluated in an experimental- controlgroup- design with three points of measurement. The effectiveness of the training was investigated by exploring learning and attributional outcomes. These constructs were operationalized by using the "Questionnaire for the assessment of verbal knowledge" (FDW) and the "Child Sexual Abuse Myth Scale" (CSAM). Results show that increased knowledge and decreased Myth Acceptance over the series of measurements is related to completing the training. Our findings provide empirical evidence for the effectiveness of the prevention training. Furthermore we were able to present a training that may be implemented in education for students in university setting. Our results are in accordance with empirical evidence that staff who had been trained on the prevention of sexual abuse shows a greater awareness and sensitivity towards sexual abuse as well as a greater commitment to put prevention and intervention plans into action. Thus the education of students and staff is an important contributor in preventing sexual abuse of children and adolescence with disabilities.
\end{abstract}

\section{Introduction}

By setting up a ,sexual child abuse "expert commission following the round table on the topic, the German Government addressed the need of research on sexual abuse of children and adolescents with disabilities.

People with disability run a higher risk of becoming sexual abuse victims [8], [43].

As their intellectual, verbal, motoric, hearing and social/emotional skills are impaired, disabled people are more vulnerable to sexual attacks, i.e. less protected against them.

In their daily life, they are highly dependent upon the support and care of other people, usually implicating clear power-dependency relations, which seems to expose them to an increased risk of sexual abuse.
Among others, the former German minister of family affairs, senior citizens, women, Dr. Christine Bergmann, presses for more training of (prospective) education professionals, especially for those working with children with disabilities, since sexual abuse not only happens in families but also within the quasisafe environment of educational institutions.

Until today, controlled studies on the effect of trainings for, e.g., (prospective) special education professionals, are lacking. These impact evaluations should assess both training content (such as knowledge of risk factors and preventive measures, detection of early warning signs, sensitization on the matter) as well as proxy variables of training design (e.g. the training's scope, its didactic elements and adaptation to the target group).

This study seeks to evaluate a training that is part of a research project "Prevent and act - sexual abuse of children and adolescents with disability" ("SeMB" www.semb.eu), funded by a research grant of the German Ministry of research and education.

The research project consists of three elements:

- Assessment of sexual abuse protective and risk factors;

- Implementation of a prevention training with children and adolescents with intellectual, physical or hearing disabilities;

- Sexual abuse prevention training of (prospective) special education professionals in schools and care institutions for people with disabilities.

The training aims are the sensitizing of (prospective) special education professionals and beyond that equipping them with skills to act professionally in a suspected case of sexual abuse.

\section{Need for professional training}

Being informed about sexual abuse of wards is a main condition for concerted action. Only a fraction of abuse cases is identified due to a lack of knowledge or expertise [2], [29], [32] $]^{1}$. For instance, Reiniger et al. (1995) asked a sample of 1400 psychologists, doctors, nurses and teachers and found

\footnotetext{
1 The authors are aware of the fact some of the references are rather old. However, they were cited due to a lack of newer studies which meet the criteria for being evidence-based.
} 
that teachers showed the least knowledge of sexual abuse [38].

Studies indicate that teachers often don't know how to adequately act in a suspected case of sexual abuse resulting in the fact that they don't share their observations [1], [17], [25]. In addition, if professionals fail to perceive sexual abuse as a problem in the institution they work at in turn may lead to ongoing sexual abuse [7], [50].

In a recent study, a thousand prospective teachers pointed out that their college classes lack information on child protection, especially on child abuse [3], [4], [19]. Also, a survey of 230 educational science and special education students indicated that within their professional group there are a lot of myths and misperceptions about sexual abuse [41].

Education professionals who work with people in need of assistance and/or disabilities also display substantial knowledge gaps and insecurities concerning the topic [5], [7], [10], [21], [39], [43], [51] - even though it is assumed that people with disabilities constitute an over proportional amount of sexual abuse victims [14], [15], [16], [23], [24], [27], [34], [43], [44], [46].

There is also a lack of knowledge concerning which legal steps to take. Only $25 \%$ of the surveyed care professionals indicated legal action as a possible measure in a suspected case of sexual abuse. Altogether, it seems that care institutions for people with disabilities often do not have an official binding concept on client sexual abuse protection [5], [23], [48].

Lack of knowledge obstructs both (suspected) sexual abuse cases disclosure and adequate professional sexual abuse intervention conduct. Teachers with professional know-how are more likely to pass on sexual abuse reports [17].

The majority of abused children and adolescents disclose to their teachers [42], [45], therefore, a timely and high quality training for (prospective) teachers is required. The first element should be a general awareness training that provides factual knowledge on sexual abuse. Sexual abuse denial with phrases like "There's nothing like that at our school" can lead to sexual abuse cases being ignored. On the other hand, care institution staff indicates that they feel responsible for the detection and prevention of sexual abuse [31].

First studies back up that professionals who (frequently) attend training on sexual abuse show increased factual knowledge [20], [22], [26], [28], [30], [35]. After a mere four hour training, care professionals for clients with disabilities showed a slight change in knowledge on sexual abuse as well as in attitudes on sexuality and sexual abuse of people with disabilities [10]. The presented training builds on the described findings and seeks to extend the research in that area.

\section{Methodology}

\subsection{The training}

The training consists of two four hour parts, taking place on consecutive days. The first part of the training focusses on basic knowledge and the second on know-how. Altogether, the training has eleven elements, each directed at different learning goals (refer Table 1) and taught via different didactical methods. Importance is also put on actively involving the participants through exercises and discussions, thus appealing to different learning styles [37]. Contents are adapted to specific professional fields. All training elements are concluded with take home messages. Several researchers and the project's advisory board reviewed this training and a group of teachers evaluated its content and practicability.

\subsection{Procedure}

The training's outcome is evaluated by a treatment- control- group design with repeated measurements (pre-, post- and follow-up measurement after six weeks).

Experimental group recruiting and sampling was carried out during the 2014 University of Cologne (Germany) summer term (March - June) at the Faculty of Human Science, within the student body of the Department of Special Education and Rehabilitation. The training was a voluntary class for prospective teachers in their $4^{\text {th }}$ or $5^{\text {th }}$ semester, i.e. special education students (Bachelor of Arts and the discontinued degree of the German "Staatsexamen") offered as a complementary course to the class they enrolled in; either "hearing and communication" (henceforth abbreviated "HK"), "body and motor development" ("KME") or "intellectual development" ("GE"). The university`s intranet ("KLIPS") randomly assigned the students to one of the three classes.

Control group recruiting and sampling was carried out during summer term 2014 (June and July). Here it has to be mentioned that randomisation of groups was not feasible.

To incentivize participation and avoid missing data records, the students were required to attend all three points of measure in order to receive the certificate of attendance for the class they originally had enrolled in; i.e. only after having participated in the follow-up assessment did the students receive their certificate for participating in the training.

As a sign of appreciation for their commitment, control group participants were invited to a two-hour seminar on "sexual abuse of children and adolescents with disabilities", which was free of charge and took place after the follow-up measurement. 
Table 1. Training elements and learning goals

\begin{tabular}{|c|c|}
\hline Training element & Learning goals \\
\hline $\begin{array}{l}\text { 1. Definition and sexual abuse } \\
\text { rates }\end{array}$ & $\begin{array}{l}\text { Participants learn the difference between „hands off” and „hands on" } \\
\text { abuse cases and realize that cases without actual physical contact between } \\
\text { offender and victim can also count as sexual abuse. } \\
\text { They also learn that people with disabilities are statistically three to four } \\
\text { times more likely to become sexual abuse victims compared to people } \\
\text { without disabilities. }\end{array}$ \\
\hline $\begin{array}{l}\text { 2. Sexual rights and sexual } \\
\text { development of children and } \\
\text { adolescents with disabilities }\end{array}$ & $\begin{array}{l}\text { Participants realize that children and adolescents with disabilities have the } \\
\text { right to experience sexuality and sexual desire. They come to know that } \\
\text { children and adolescents should be in a safe environment and guided when } \\
\text { experiencing sexuality and that exchanging sexual experiences can happen } \\
\text { only by mutual agreement. } \\
\text { Participants learn that the social, emotional and physical development of } \\
\text { disabled children and adolescents with disability varies a lot inter } \\
\text { individually and that those individual and situational aspects should } \\
\text { always be taken into consideration. }\end{array}$ \\
\hline $\begin{array}{l}\text { 3. Risk factors in children and } \\
\text { adolescents with disabilities }\end{array}$ & $\begin{array}{l}\text { Participants come to know that people with disabilities are much more } \\
\text { vulnerable because of their condition. They know about the range of risk } \\
\text { factors and are able to name them. }\end{array}$ \\
\hline $\begin{array}{l}\text { 4. Institutional and structural } \\
\text { risk factors }\end{array}$ & $\begin{array}{l}\text { Participants know about institutional and structural risk factors that can } \\
\text { promote sexual abuse. They are able to deduce solutions and protective } \\
\text { measures. }\end{array}$ \\
\hline 5. Offenders & $\begin{array}{l}\text { Participants know that there are different types of offenders and that they } \\
\text { usually take advantage of a system and plan the abuse over a long time } \\
\text { and/or that abuse may develop over time. }\end{array}$ \\
\hline $\begin{array}{l}\text { 6. Behavioral changes and } \\
\text { problems as a consequence of } \\
\text { sexual abuse }\end{array}$ & $\begin{array}{l}\text { Participants know that children and adolescents can show behavioral } \\
\text { changes and problems when being or having been abused. They are able to } \\
\text { assess that these changes can only sometimes be directly attributed to } \\
\text { sexual abuse. They know that most behavioral changes that are commonly } \\
\text { related to sexual abuse can also occur due to other reasons. Therefore, } \\
\text { participants learn the range of indicators while knowing that there are is } \\
\text { only little scientific proof that those indicators can serve as unequivocal } \\
\text { evidence for sexual abuse. Participants develop alertness for sudden } \\
\text { behavioral changes. }\end{array}$ \\
\hline $\begin{array}{l}\text { 8. Leading a disclosure- } \\
\text { conversation }\end{array}$ & $\begin{array}{l}\text { Participants know what elements a disclosure conversation must } \\
\text { incorporate and what they should refrain from. } \\
\text { They know how the conversation should be adapted depending on the } \\
\text { client's disabilities. } \\
\text { Also, participants know how to create an atmosphere in the institution they } \\
\text { work in that encourages reports about (sexual) abuse. }\end{array}$ \\
\hline $\begin{array}{l}\text { 9. Procedures in a suspected } \\
\text { sexual abuse case }\end{array}$ & $\begin{array}{l}\text { Participants learn that the most important rule when dealing with suspected } \\
\text { sexual abuse cases is to consult professional help. They know that they are } \\
\text { legally entitled to professional consultation by the respective legally } \\
\text { entrusted child protection personnel. Participants learn that their institution } \\
\text { needs to design a standardized procedure for suspected sexual abuse cases } \\
\text { and what those procedures need to incorporate. }\end{array}$ \\
\hline $\begin{array}{l}\text { 10. Design activating and } \\
\text { meaningful prevention } \\
\text { measures for children and } \\
\text { adolescents }\end{array}$ & $\begin{array}{l}\text { Participants know that effective prevention measures constitute a } \\
\text { protection against sexual abuse. } \\
\text { They know the specific key factors of prevention measures for children } \\
\text { and adolescents. }\end{array}$ \\
\hline $\begin{array}{l}\text { 11. Institutional preventional } \\
\text { measures }\end{array}$ & $\begin{array}{l}\text { Participants know the standards for institutional prevention measures } \\
\text { defined by the expert commission. } \\
\text { They know how to translate those standards into institutional activities } \\
\text { after the training. }\end{array}$ \\
\hline
\end{tabular}




\subsection{Sample}

The total sample size of $N=391$ consisted of $n=138$ students with the profession "intellectual development", $n=100$ students with the profession "hearing and communication" and $n=153$ students with the profession of "body and motor development". In the treatment group $n=211$ and in the control group $n=180$ data were collected. For implementing the treatment 12 training trails with 12-17 participants were performed.

The sample's mean age was $24.11(S D=3.116$, range: $20-48$ years) and consisted of $17.4 \%$ male and $82.6 \%$ female students $(n=68$ and 322, respectively). Most of the participants $(n=395$, $90.5 \%$ ) possessed prior work experience with disabled children and adolescents, either through internships $(n=295)$, part time employment $(n=159)$, freelance volunteer work $(n=127)$ or full time civil service commitment $(n=144)$. Additionally, $20.1 \% \quad(n=78)$ were already fully trained professionals of some kind. More than $80 \%$ reported to have very little to little know-how on the topic; and $70 \%$ indicated to have very little to little theoretical knowledge on the topic. However, $86 \%$ stated a strong to very strong interest in the topic.

\subsection{Measurements}

The test battery consisted of the "Declarative Knowledge Questionnaire" (FDW) and a German translation of the "Child Sexual Abuse Myth Scale" (CSAM) [12]. Additionally, during pre-sampling socio-demographic variables and the beforementioned interest and experience in the topic via a five-point Likert scale (1="very little" to 5="very big") were assessed.

Post-sampling additionally included the "Training Satisfaction Questionnaire" (FBT), an integrated version of the standardized class evaluation form of the University of Cologne and of the "Questionnaire for Professional Training Evaluation" (Q4TE) [18].

Treatment integrity and experimental validity [33], [40], [49] were measured via the "Trainers" Questionnaire"(DADT). It also comprised items on the trainers ' general satisfaction with the training.

3.4.1. Declarative Knowledge Questionnaire. The "FDW" was specifically designed for the study in order to measure participants declarative knowledge on the training's topic. The questionnaire consists of open-ended questions (e.g. "List three types of sexual abuse that do not involve body contact"; "List three typical strategies from offenders") that are rated dichotomously ("right" and "wrong"). The final score is obtained by summing up all correctly answered items; scores range from 0 to 24 . The questionnaire was piloted on a student sample of $N=132$ and then changed according to a thorough item analysis. The questionnaire`s internal consistency is $\alpha=.855$ and can therefore be considered "good" [13].

\subsubsection{Child Sexual Abuse Myth Scale.} Dysfunctional sexual abuse stereotypes and attitudes were measured with a German version of the Child Sexual Abuse Myth Scale (CSAM). The questionnaire comprises 15 items (e.g. "Sexual child abuse is caused by hardship like unemployment, poverty and alcoholism"; "Teenage girls that dress inappropriately basically are asking to be sexually abused") that are answered on a fivepoint Likert scale (1="I don't agree at all" to 5="I completely agree"). There is a total score called "Myth Acceptance" as well as subscale scores, namely (1) Blame Diffusion, (2) Denial of Abusiveness and (3) Restrictive Stereotypes. High scores operationalize a high Myth Acceptance.

As recommended by the authors, the original English version was translated to German and then translated back to secure semantic and content equivalence. In order to culturally adapt the questionnaire and ease the introduction to the topic, the order of two items was changed.

The pilot survey with $N=402$ students and subsequent factor analysis were not able to confirm the factor structure as validated by Collings, therefore, merely the sum score "Myth Acceptance" was used for data analysis in this study. The scale's internal consistency ranges at a $\alpha=.732$, thus comparable to the English versions [12] and can also be considered good [13].

3.4.3. Training Satisfaction Questionnaire. To measure the participants` general satisfaction with the training, the post and follow-up test battery included the Training Satisfaction Questionnaire. As mentioned before, this questionnaire comprises items of the standardized class evaluation form of the University of Cologne. The items (e.g. "The content was well structured and comprehensive", "The trainer reacted to the participants' statements in a qualified manner") were specifically adapted to the content of the training and rated on a 5-point Likert scale (1="I don`t agree at all" to 5="I completely agree"). High scores operationalize a high satisfaction.

This questionnaire was piloted on a group of $N=132$ students and was changed according to the item analysis. According to Cortina (1993), the internal consistency $\alpha=.936$ is excellent.

Also, the questionnaire comprises items of the "Questionnaire for Professional Training Evaluation" (Q4TE) [18]. This instrument was originally developed as a Human Resource (HR) training evaluation survey tool, however, can be applied to any kind of training. For the study, the Q4TE was changed significantly. For instance, item wording was changed; and an item that was considered inappropriate for the topic was removed ("The training was fun"). Therefore, the original 
psychometric parameters supplied by the authors could not be considered valid for this study. The nine adapted Q4TE items used in the Training Evaluation Questionnaire (e.g. "I will keep the training in good memory"; "Having participated in the training is very beneficial for my job"; "I'm able to apply the training's content on the job") were to be evaluated by on a five-point Likert scale ( $1=$ "I don't agree at all" to 5="I completely agree"). Four items assessed the immediate reaction to the training, including satisfaction, usefulness and learning outcome. Those were used in the posttesting. Long-term reaction such as changes in work behavior, subjectively perceived skills and outcomes at institutional/organizational level was assessed via five items as part of the follow-up testing. The two sub scales' average scores have good internal consistency (sub scale "short-term effect of training" $\alpha=.896$ and "long-term effect of training" $\alpha=.793$, respectively). Because of the small amount of items, the analysis of the questionnaire`s further sub scales provided by the authors was not valid.

3.4.5. Trainers' assessment of treatment integrity and general training satisfaction. After each training, the trainers completed the "Trainers" Questionnaire" (DATD). Each of the eleven element was assessed on whether it was taught according to the manual and whether the provided material was put to use $(0=$ "not at all", $1=$ "in part", $2=$ "completely"). If elements had not been taught, the reason had to be stated ("no interest/no motivation shown by participants", "lack of time" or "other"). Also, the trainers had to indicate, to which degree additional content was covered during the training.

After the complete training, the trainers had to assess their general satisfaction with the training. The design of this questionnaire was also guided by the standardized material used by the University of Cologne.

\subsection{Hypotheses and statistical analysis}

The study explores the following hypotheses:

1. Hypothesis 1: Students that participated in the prevention training know more about the topic than students that did not participated.

2. Hypothesis 2: Students that participated in the prevention training show less Myth Acceptance than students that did not participated.

IBM SPSS Statistics 22.0 (IBM Cooperation, 2013) was used for data analysis and in line with the "perprotocol-analysis" any records with missing data were excluded. Altogether, there were $n=353$ (90.3\%) complete records of both pre- and post- testing. Out of those, $47.1 \%$ were excluded for the lack of follow-up data, so that eventually $n=207$ $(52.9 \%)$ records were used for data analysis.

The hypotheses were tested with multifactorial repeated measures ANOVA. According to the hypotheses, significant effects of the interaction between point of measurement and group were expected for the variables "Declarative Knowledge" and "Myth Acceptance". Effect sizes were then calculated to allow for the interpretation of mean differences. In this study, eta square $\left(\eta^{2}\right)$ was used. $\eta^{2} \geq .10$ is considered a small, $.25-.30$ a medium and $\eta^{2} \geq .40$ a large effect [11], [36].

\section{Results}

\subsection{Treatment integrity and satisfaction with the training}

There can be reported a high fidelity to treatment of $.986(\mathrm{SD}=.0324)$ over all training trails. Thus, $98.61 \%$ of the trainings were implemented due to manual. In $99.24 \%$ (quote: $.992, \mathrm{SD}=.0262$ ) of the cases the intended material were applied.

The results show that Fidelity measured with the "DATD" was nearly $100 \%$ and between training trails no variability in terms of treatment implementation was discovered. Thereby internal validity can be considered as assured.

A high rate of satisfaction with the training from perspective of trainers can be reported. Satisfaction with implementation were over all training trails high (median=4.00, $\mathrm{SD}=.492$ ). Also no significant differences between trainers were detectable (nonparametric Kruskal-Wallis test: $\chi 2(3$; $\mathrm{N}=12)=5.156, \mathrm{p}=.161$ ).

Right after the training, general training satisfaction was rated at $\mathrm{M}=4.56(\mathrm{SD}=.567)$. The "short term reaction" scale of the Q4TE had a postmean of $\mathrm{M}=4.49$ ( $\mathrm{SD}=.646)$. The follow-up longterm reaction to the training was $\mathrm{M}=3.67$ ( $\mathrm{SD}=$ .512) (see Table 2).

Analysis shows that the participating students were very satisfied with the training. Additionally, they indicated that they considered the training's content very useful and that in the future they will apply what they have learned on their jobs. Those results hint at the positive effects at both the participants` personal as well as their professional level.

Declarative Knowledge. For the treatment group the declarative knowledge pre-training mean resulted in $\mathrm{M}=12.82$ ( $\mathrm{SD}=4.944)$ and the posttraining mean in $\mathrm{M}=19.67$ ( $\mathrm{SD}=3.313$ ). The followup mean amounted to $\mathrm{M}=18.79(\mathrm{SD}=3.789)$. In contrast the scores of the controllgroup remain nearly unchanged: pre mean $\mathrm{M}=11.35$ ( $\mathrm{SD}=3.397$ ), post mean $\mathrm{M}=11.79(\mathrm{SD}=3.803)$ and follow-up mean $\mathrm{M}=11.35(\mathrm{SD}=3.811)$ (see Figure 1 and Table 2). 


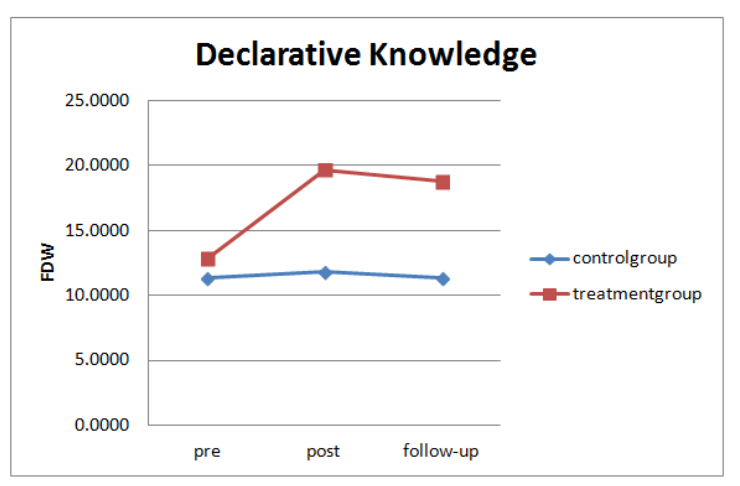

Figure 1. Mean declarative knowledge over the three points of measurements

The ANOVA carried out to test the first hypothesis showed a significant effect of interaction between point of measurement and group $(F=137.277$; $\left.d f_{\text {korr }}=1.955 ; p=.000 ; \eta^{2}=.402\right)$. The effect size can be considered large.

The results show that having participated in the training not only lead to a significant but also to a relevant increase in declarative knowledge in the participating student sample, that was still present, i.e. significant, six weeks later.

The study was able to show that there is an extensive factual knowledge on the topic of sexual abuse of disabled children and adolescents immediately after as well as six weeks post training. In comparison to students that did not participate on the training the participating students were able to list risk factors in disabled children and adolescents as well as in institutions, among others.

\subsection{Myth Acceptance}

For the treatment group Pre-testing showed a Myth Acceptance mean of $M=1.59(S D=.373)$, post-testing showed a decrease to $M=1.44$ ( $S D=$ .309) and follow-up a further decrease to $M=1.37$ $(S D=.291)$. The Score of the control group remains nearly unchanged (pre mean $M=1.63(S D=.357)$, post mean $M=1.55$ ( $S D=.307)$, follow-up-mean $M=1.61(S D=.377)$ (see Figure 2 and Table 2).

Hypotheses testing also resulted in a significant effect of interaction between point of measurement and group $\left(F=11.195 ; d f_{\text {korr }}=1.970\right.$; $\left.p=.000 ; \eta^{2}=.054\right)$, however the effect size can be regarded small (see Table 2 ).

Those results point out that "Myth Acceptance" was significantly reduced immediately after and even six weeks after the training. However, the effect size is rather small. One reason could be the sample being very homogenous considering age, sex and field of study.

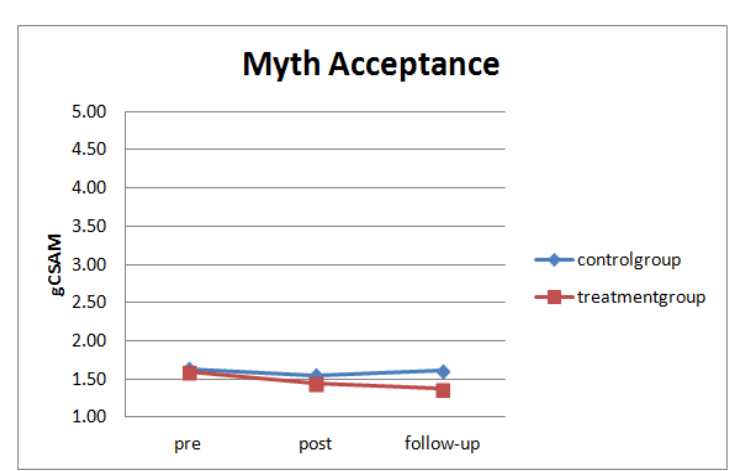

Figure 2: Mean Myth Acceptance over the three points of measurements

\section{Discussion and Conclusion}

Prevention training has to start as early as possible in the education of prospective special education professionals. In order to avert sexual abuse, factual knowledge and know-how are a prerequisite for them to timely detect institutional and individual sexual abuse risk factors and warning signals.

A prevention training on sexual abuse of children and adolescents with disabilities for special education students and professionals working in care institutions for children and adolescents with intellectual, physical or hearing disability was developed at the University of Cologne. Preliminary results of the training indicate positive effects on factual knowledge and know-how on prevention of sexual abuse. Data analysis showed a significant relationship between completing the training and an increase in knowledge over time in comparison to completing no training. Furthermore, the participants' attributions also changed significantly in the intended manner.

However, the two-month follow-ups scores in the Declarative Knowledge Scale significantly decreased compared to the posttest, which was conducted rather shortly after the intervention. This is an important negative result, suggesting that the training knowledge deteriorates over time. This phenomenon could be absorbed by obligatory implementation of prevention contents in the University's curriculum. Future teachers would start their teachers training and practical teaching with a great knowledge on the prevention of sexual abuse. Nonetheless, no conclusion can between drawn between the increased (or decreased) knowledge of the trained University students and their actual behavior at school once they might be confronted with a suspect of abuse (if they actually recognize or report cases of sexual abuse).

These results are preliminary and cannot be generalized. Since the sample merely consists of special education students, on-the-job sexual abuse preventive skills acquired by the training cannot be reliably predicted. Furthermore, the dropout rate is relatively high and there is a lack of information with regard to a possible confunding with the 
Table 2. Statistical indicators at each point of measure (pre, post, follow-up) for each survey instrument

\begin{tabular}{|c|c|c|c|c|}
\hline Outcome & group & t0 (pre) & t1 (post) & t2 (follow-up) \\
\hline \multirow[t]{3}{*}{$\begin{array}{l}\text { Declarative } \\
\text { knowledge (FDW) }\end{array}$} & EG $(n=139)$ & $\begin{array}{l}M=12.82 \\
(S D=4.944)\end{array}$ & $\begin{array}{l}M=19.67 \\
(S D=3.313)\end{array}$ & $M=18.79(S D=3.789)$ \\
\hline & $\mathrm{KG}(n=65)$ & $M=11.35(S D=3.397)$ & $\begin{array}{l}M=11.79 \\
(S D=3.803)\end{array}$ & $M=11.35(S D=3.811)$ \\
\hline & $\begin{array}{l}\text { Interaction } \\
\text { timepoint of } \\
\text { measurment*group }\end{array}$ & \multicolumn{3}{|c|}{$F=137.277 ; d f=1.955 ; p=.000^{* * *} ; \eta 2=.402$} \\
\hline \multirow[t]{3}{*}{$\begin{array}{l}\text { Myth Acceptance } \\
\text { (CSAM) }\end{array}$} & EG $(n=136)$ & $\begin{array}{l}M=1.59 \\
(S D=.3726)\end{array}$ & $\begin{array}{l}M=1.44 \\
(S D=.309)\end{array}$ & $\begin{array}{l}M=1.37 \\
(S D=.291)\end{array}$ \\
\hline & $\mathrm{KG}(n=65)$ & $\begin{array}{l}M=1.63 \\
(S D=.357)\end{array}$ & $\begin{array}{l}M=1.55 \\
(S D=.307)\end{array}$ & $\begin{array}{l}M=1.61 \\
(S D=.377)\end{array}$ \\
\hline & $\begin{array}{l}\text { Interaction } \\
\text { timepoint of } \\
\text { measurment*group }\end{array}$ & \multicolumn{3}{|c|}{$F=11.195 ; d f=1.970 ; p=.000^{* * *} ; \eta 2=.054$} \\
\hline \multicolumn{5}{|c|}{${ }^{*}$ sig. $p<.05 ;{ }^{* *}$ sig. $p<.01 ; * * *$ sig. $p<.001$} \\
\hline
\end{tabular}

treatment. Beyond that, further analyses on confounding variables and moderator and mediator variables, such as prior professional experience as well as interest in the topic are required. As well multilevel modeling should be performed. Mixed models have some meaningful benefits especially for repeated measures designs compared with analysis of variance techniques [47]. First of all predictors from different levels may be implemented into the model so that full information of hierarchical data can be used. Thus, it would be possible to interpret individual response patterns over the repeated measurements. Another advantage is that there is no requirement for complete data over sequence of measurements and multilevel analysis may be inserted when assumption of independence of errors and shericity (heterogeneity of variance) is violated; above all in repeated measure designs these assumptions were harmed frequently. For example, the fact that participants had passed the same training trail means that response from these participants were not independent. The result of ignoring violation of the assumption of independence of errors would be increased Type I error and due to this increased validation of statistical interpretation as well (see, [6], [9]).

In terms of the fidelity it should be noted, that treatment integrity was assessed by self-report of the trainers. Self- reported data may be influenced by social desirability and memory effects. It is recommended the implicit elevation should be supplemented with direct surveys, for example using video analysis [33], [40].

Further limitations of the study include selection bias as the participants were voluntarily taking part in the training or the large drop-off of study subjects.

The results found in this study show that timely training of prospective special education professionals leads to an increased knowledge about sexual abuse (i.e. its prevention and dealing with suspected cases). This and can make an important contribution to the prevention of sexual abuse of children and adolescents with disabilities and should thus be an obligatory training for every future teacher and person working with children and adolescents with disabilities.

\section{References}

[1] Abrahams, N, Casey, K. \& Daro, D. (1992). Teachers' knowledge, attitudes, and beliefs about child abuse and its prevention. Child Abuse \& Neglect, 16 (2), 229-238.

[2] Bavolek, S. (1983). Why aren't school personell reporting child abuse in Wisconsin? Teacher Education and Special Education, 6 (1), 33-38.

[3] Baginsky, M. (2003). Newly qualified teachers and child protection: A survey of their views, training, and experiences. Child Abuse Review. 12 (2), 119-127.

[4] Baginsky, M. (2005). Training teachers to safeguard children: Developing a consistent approach. Child Abuse Review. 14 (5), 317-330.

[5] Bange, D. (2012). Kinder mit sexuellen Verhaltensauffälligkeiten. Kindesmisshandlung und vernachlässigung, 15(1), 4-29.

[6] Barcikowski, R. (1981). Statistical power with group mean as the unit of analysis. Journal of Educational Statistics, 6, 267-285. 
[7] Beck, H. (2012). Muster Handlungsempfehlung zum Umgang mit Grenzverletzungen, sexuellen Übergriffen und sexueller Gewalt gegen Menschen mit Behinderungen in voll- und teilstationären Einrichtungen der Behindertenhilfe - zur Erprobung in der Praxis. Frankfurt am Main.

[8] Bergmann, C. (2011). Abschlussbericht der Unabhängigen Beauftragten zur Aufarbeitung des sexuellen Kindesmissbrauchs. Berlin: Geschäftsstelle der Unabhängigen Beauftragten zur Aufarbeitung des sexuellen Kindesmissbrauchs.

[9] Blair, R.C. \& Higgins, J.J. (1986). Comment on "Statistical power with group mean as the unit of analysis. Journal of Educational Statistics, 11, 161-169.

[10] Bowman, R. A., Scotti, J. R., \& Morris, T. L. (2010). Sexual abuse prevention: A training program for developmental disabilities service providers. Journal of Child Sexual Abuse: Research, Treatment, \& Program Innovations for Victims, Survivors, \& Offenders, 19, 119-127.

[11] Cohen, J. (1992). A power primer. Psychological Bulletin, 112, 155-159.Collings, S. J. (1997). Development, Reliability, and Validity of the Child Sexual Abuse Myth Scale. Journal of Interpersonal Violence, 12(5), 665-674.

[12]Collings, S.J. (1997). Development, Reliability, and Validity of the Child Sexual Abuse Myth Scale. Journal of Interpersonal Violence, 12 (5), 665-674.

[13] Cortina, J. M. (1993). What is coefficient alpha? An examination of theory and applications. Journal of Applied Psychology, 78, 98-104.

[14] Conen, M. L. (1995). Sexual abuse by staff of inpatient facilities for children and adolescents. Praxis Der Kinderpsychologie Und Kinderpsychiatrie, 44(4), 134-140.

[15] Conen, M.-L. (2002). Institutionen und sexueller Missbrauch. In D. Bange \& W. Körner (Eds.), Handwörterbuch Sexueller Missbrauch (pp. 196-201). Hogrefe Verlag.

[16] Fegert, J. M., \& Wolff, M. (2006). Sexueller Missbrauch durch Professionelle in Institutionen: Prävention und Intervention- ein Werkbuch. Weinheim: Juventa.

[17] Greytak, E. (2009). Are Teachers Prepared? Predictors of Teachers' Readiness to Serve as Mandated Reporters of Child Abuse. Publicly accessible Penn Dissertations.

[18] Grohmann, A., \& Kauffeld, S. (2013). Evaluating training programs: Development and correlates of the Questionnaire for Professional Training Evaluation. International Journal of Training and Development, 17(2), 135-155.

[19] Goldman, J., Bradley, G. (2011). Assessing primary school student-teachers' pedagogicimplementations in child sexual abuse protection education. European Journal of Psychology of Education, 26 (4), 479-493.
[20] Hanson, R. F., Ralston, E., Self-Brown, S., Ruggiero, K. J., Saunders, B. E., Love, A. G, Hawkins, R. \& McCallum, C. (2001). Mandatory Notification Training for suspected child abuse and neglect in South Australian schools. Child Abuse \& Neglect, Vol 25(12), pp.1603-1625.

[21] Hames, A. (1996). The effects of experience and sexual abuse training on the attitudes of learning disability staff. Journal of Intellectual Disability Research, 40, 544-549.

[22] Hawkins, R. \& McCallum, C. (2001). Effects of mandatory notification training on the tendency to report hypothetical cases of child abuse and neglect. Child Abuse Review, 10, 301-322.

[23] Helming, E., Kindler, H., Langmeyer, A., Mayer, M., Mosser, P., Entleitner, C., Schutter, S. \& Wolff, M. (2012). Sexuelle Gewalt gegen Mädchen und Jungen in Institutionen. Abschlussbericht. Deutsches Jugendinstitut.

[24] Joyce, T. A. (2003). An audit of investigations into allegations of abuse involving adults with intellectual disability. Journal of Intellectual Disability Research, 47(8), 606-616.

[25] Kenny, M. C. (2001). Child abuse reporting: teachers' perceived deterrents. Child Abuse \& Neglect 25 (1), 81-92.

[26] Kleemeier, C., Webb, C., Hazzard, A. \& Pohl, J. (1988). Child sexual abuse prevention: Evaluation of a teacher training model. Child Abuse \& Neglect, Vol 12(4), 1988. pp.555-561.

[27] Knutson, J., \& Sullivan, P. (1993). Communicative disorders as a risk factor in abuse. Topics In Language Disorders, 13(4), 1-14.

[28] McGrath, P., Cappelli, M., Wiseman, D., Khalil, N. \& Allan, B. (1987). Teacher awareness program on child abuse: Randomized controlled trial. Child Abuse \& Neglect, Vol 11(1), pp.125-132.

[29] McIntyre, T. (1987). Teacher awareness of child abuse and neglect. Child Abuse \& Neglect, 11 (1), 133135.

[30] McIntyre, T.C. (2000). Teacher awareness of child abuse and neglect. Child Abuse \& Neglect, Vol 11(1), 1987, 133-135.

[31] Oosterhoorn, R. \& Kendrick, A. (2001). No sign of harm: Issues for disabled children communicating about abuse. Child Abuse Review, 10 (1), pp. 243-253.

[32] O'Toole, R., Turbett, P. \& Nalepka, C. (1983). Theories, professional knowledge, and diagnosis of cild abuse. The dark side of families: curent family violence research, 349-362.

[33] Perepletchikova, F., Hilt, L. M., Chereji, E., \& Kazdin, A. E. (2009). Barriers to implementing treatment integrity procedures: Survey of treatment outcome researchers. Journal of Consulting and Clinical Psychology, 77(2), 212-218. 
[34] Rabold, S. \& Görgen, T. (2007). Misshandlung und Vernachlässigung älterer Menschen durch ambulante Pflegekräfte. Zeitschrift für Gerontologie und Geriatrie, 40 (5), 366-374.

[35] Randolph, M. K. \& Gold, C. A. (1994). Child sexual abuse prevention: Evaluation of a teacher training program. School Psychology Review, Vol 23(3), 1994. pp.485-495.

[36] Rasch, Friese, Hofmann, \& Neumann. (2010). Quantitative Methoden. Band 2 (3. Auflage.). Heidelberg: Springer.

[37] Reich, K. (2012). Konstruktivistische Didaktik: Das Lehr- und Studienbuch mit Online-Methodenpool (5th ed.). Pädagogik und Konstruktivismus. Weinheim: Beltz.

[38] Reiniger, A., Robison, E. \& McHugh, M. (1995). Mandated training of professionals: a means for improving reporting of suspected child abuse. Child Abuse \& Neglect 19 (1), 63-69.

[39] Röhrig, M. (1993). Wahrnehmung und Einstellung zur sexuellen Gewalt bei Mitarbeiter/innen in sonderpädagogischen Einrichtungen. Sexuelle Gewalt und Behinderung. Hamburg: Dr. Kovac-Verlag.

[40] Sanetti, L. M. H., \& Kratochwill, T. R. (2011). An evaluation of the treatment integrity planning protocol and two schedules of treatment integrity self-report: Impact on implementation and report accuracy. Journal of Educational \& Psychological Consultation, 21(4), 284-308.

[41] Scharmanski, S., Bienstein, P. \& Verlinden, K. (in preperation). Überprüfung von Mythen und Attributionen zum sexuellen Missbrauch. Eine Evaluation studentischer Einstellungen.

[42] Schönbucher, V., Maier, T., Mohler-Kuo, M., Schnyder, U., \& Landolt, M. A. (2012). Disclosure of Child Sexual Abuse by Adolescents A Qualitative InDepth Study. Journal of Interpersonal Violence, 27(17), 3486-3513.

[43] Schröttle, M., Hornberg, C., Glammeier, S., Sellach, B., Kavemann, B., Puhe, H., \& Zinsmeister, J. (2012). Lebenssituation und Belastungen von Frauen mit Beeinträ chtigungen und Behinderungen in Deutschland. BMFSFJ.

[44] Sobsey, D. (1994). Crime prevention and personal safety. In M. Agran, N. E. Marchand-Martella, \& R. C. Martella (Eds.), Promoting health and safety: Skills for independent living. (pp. 193-213). Baltimore, MD US: Paul H Brookes Publishing.

[45] Stromsness, M. M. (1994). Sexually Abused Women with Mental Retardation: Women \&; Therapy, 14(3-4), 139-152.

[46] Sühlfleisch, U., Martinsohn-Schittkowski, W., Thomas, H., Klein, S., Wawrok, S., Wölkerling, U., Ziegenhain, U., et al. (2002). Sexueller Missbrauch in Institutionen - ein besonders heikles Thema? - Ergebnisse einer Befragung. Behindertenpädagogik, 41(4), 429-435.
[47] Tabachnick, B. \& Fidell, L. (2007). Using multivariate statistics (5. ed.). Pearson: Boston, Mass. [u.a.].

[48] Walker-Descartes, I., Sealy, Y. M., Laraque, D., \& Rojas, M. (2011). Caregiver perceptions of sexual abuse and its effect on management after a disclosure. Child Abuse \& Neglect, 35(6), 437-447.

[49] Weck, F., Bohn, C., Ginzburg. Denise M., \& Stangier, U., (2011). Behandlungsintegrität: Implementierung,Messung,Evaluationund Zusam menhängezum Therapieerfolg. Verhaltenstherapie, 21(2), 99-107.

[50] Zemp, A. (1997). Tabuisierte Not. Sexuelle Ausbeutung von Mädchen und Frauen mit Behinderung. Zürich.

[51] Zinsmeister, J. (2003). Sexuelle Gewalt gegen behinderte Menschen und das Recht: Gewaltprävention und Opferschutz zwischen Behindertenhilfe und Strafjustiz.Dokumentation des Potsdamer Rechtssymposiums.Leverkusen:Leske\&Budrich. 